\title{
Design \& Development of Mechanisum for Making Granuals From Recycled Molten Plastic
}

\author{
Prof. V. D. Dhopte \\ Under the Guidance of \\ Assistant professor of department of Mechanical Engineering, \\ K.D.K college of Engineering Nagpur \\ Department of \\ (Mechanical Engineering) \\ K.D.K College of Engineering. \\ Rashtrasanta Tukdoji Maharaj Nagpur University, Nagpur-440032, India.
}

\author{
(4M328) Rohit P. Shende \\ (4M329) Sagar S. Kale
}

Authors:

(4M332) Saurabh D. Ramteke

(4M337) Shubham K. Ambule

\author{
(4M344) Khushal M. Khadgi \\ (4M369) Rahul M. Gupta
}

\begin{abstract}
Plastic waste is a biggest problem arising now a days . since it pollutes the environment and reduce the quality of natural resources like soil, water, air ,etc . so it is a need of time to recycle the waste plastic into a product. But there is another problem associated with the conventional method of recycling, it has many demerits and disadvantages. like a number of processes required is more .be requires high power consumption and large floor space is required for installation of setup ,cost of recycling is higher.

Our project aims towards the above following point by introducing an attachment to the machine which combine the number of processes required for recycling. Which directly reduce the number of machines results in reduction of power consumption. since the number of stages are combined small floor space required for the setup installation. This attachment will directly reduce the cost of recycling and avail the more efficient and cost effective process for plastic recycling.
\end{abstract}

\section{INTRODUCTION:}

Thermoplastic is highly recyclable plastic also called a thermo-softening plastic. It is used in a wide variety of applications, including food packaging, textiles, plastic parts, reusable containers, and automotive components.

Plastic recycling refers to the process of recovering waste or scrap plastic and reprocessing the materials into functional and useful products. This activity is known as the plastic recycling process. The goal of recycling plastic is to reduce high rates of plastic pollution while putting less pressure on virgin materials to produce brand new plastic products.

Plastic recycling plant is essential for recycling of waste plastic. As the level of plastic waste is tremendously increasing and the small industries are using the process for recycling the waste plastic is very slow and costly.

\section{OBJECTIVES:}

- The Developing effective pad heaters .

- Reducing the stages of plastic recycling.

- Reducing the power consumption.

- Space reduction for process.

- Improve plant efficiency.
METHODOLOGY:

The plastic granule making machine used the concept of mother and baby plastic melting machines. The process is just to cut the molten plastic into a small granule size by using a Steel circular die consisting of several holes of same size molten plastic pressed with the help of screw conveyor and from the outlet of die as soon as plastic comes out it cuts with the help of external diamond cutter attached with motor. The whole die and cutting assembly inside the water tank and water level is adjusted according to the granule cutting.

\section{PRESENT SCENARIO:}

Plastic is one of the largest sources of pollution, by volume. This waste-plastic need treatment to make it reusable.

Plastic is lightweight, versatile and durable and it not get decompose easily which cause pollution if it get recycled we can reuse it so that the pollution decreases

Nowadays, society demands that all processes, product or services must also be analyzed from an environmental point of view. Therefore it is necessary to analyze the system to determine the overall pollution associated to these activities.

Rapid growth of societies and urbanization of city over past few decades has given rise to innumerable problems. One of the major problems is the deterioration of soil quality. due to more or less unrestricted disposal of large volumes of domestic and industrial wastewater.

\section{IDENTIFICATION OF PROBLEM:}

- The conventional process used in industry is very lengthy and complex, take more time with less efficiency.

- Large space is required for that recycling plant, because of number of stages are more.

- Large amount of power is required to run the plant.

- The process is very slow and due to which the efficiency of plant is reduced. 


\section{DESIGN PROPOSAL:}

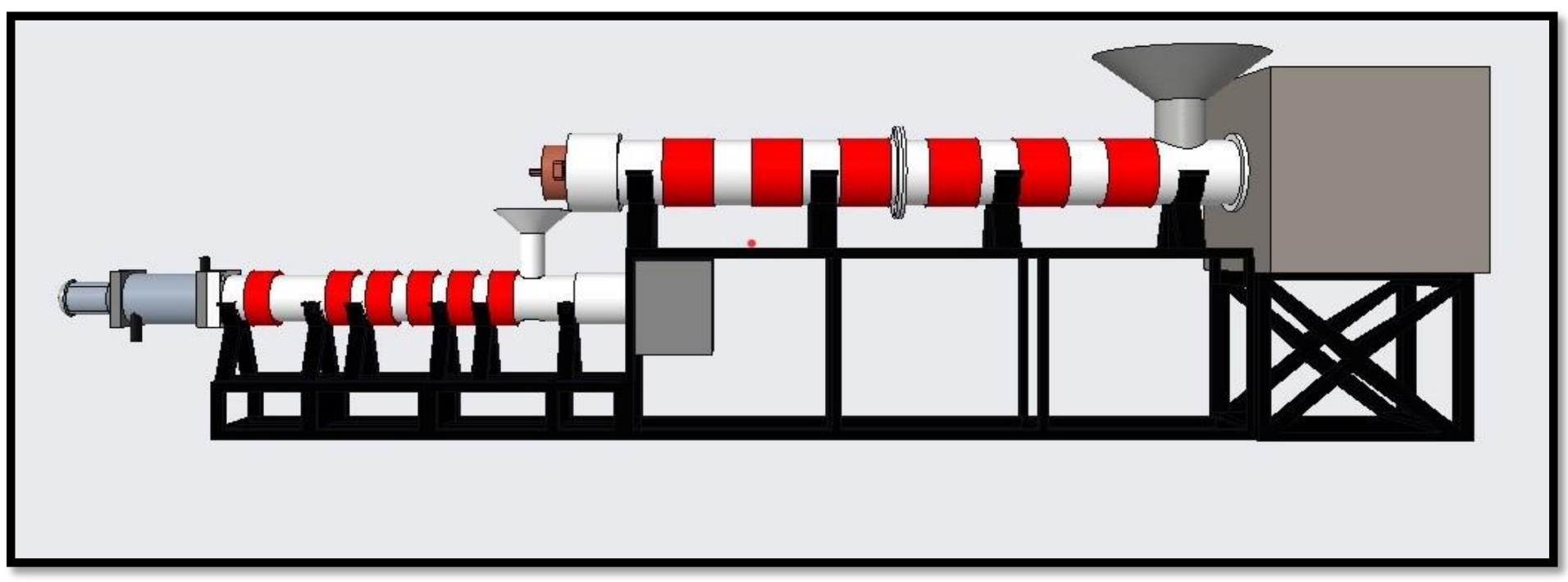

The components required for assembly of a Granule making Attachment:

- Gearbox

- Screw conveyor 50rpm (3feet long)

- $\quad$ Steel cylinder casing

- Hopper

- Circular die with 40 holes of $2 \mathrm{~mm}$ size (18.75mm diameter)

- Heaters for maintaining the desired temperature

- Face cutter mounted on die

- Sheet drum containing water as coolant

- $\quad$ Screws ,Nut and Bolts

\section{APPLICATIONS:}

- The waste polymers are efficiently processed in uniform manner and then further used for manufacturing products in various industries.

- The recycling plant is widely recommended across industries for its high output rate along with low power consumption.

\section{CONCLUSION:}

Hence, we have successfully carried out all the required calculation for the design assembly of plastic granule making machine. At the same time we have tried to use modern techniques wherever necessary. For purpose of analytical modeling the use of CREO 6.0 software has been done. While working on the project we came to know about various complexities related to the machine. All such complexities were deeply studied and a possible solution for those was successfully implemented. Working in a group together, we came to know about various aspects of team management and spirit of working together as a unit. The project is industry oriented and it has expanded our horizon regarding various industrial processes and machinery. The project was completed on time and it is serving the purpose

\section{LITERATURE REVIEW:}

1] Kamesh B. Vaidya, Mayank N. Kosurkar, Rajesh B. Pole,

Geetkumar S. Thute, Digambar R. Soni, Lokesh G. Deshmukh.( Design and Development of PlasticRecycle Machine) IJARIIE-ISSN(O)-23954396/Vol-3 Issue-2 2017.

2] Luiz Gustavo Barbosa*, Matheus Piaia, Gustavo Henrique Ceni,( Analysis of Impact and Tensile Properties of RecycledPolypropylene) International Journal of Materials Engineering 2017, 7(6): 117-120

DOI: $10.5923 /$ j.ijme.20170706.03.

3] Hisham A. Maddah King Abdulaziz University(Polypropylene as a Promising Plastic: A Review),

https://www.researchgate.net/publication/290439450.

4] Mohd Khairof Fats Bin Abd Raop(Polypropylene (Pp) Reinforced With Recycle Polyethyleneterephthalate (Pet) As An Alternative Material For New Plastic Product)

5] Abhishek Sawalkar1, Ashish Yelekar2, Yogesh Yadav3, Aakash Bisen4 ( DEVELOPMENT OF DIE FOR THE PRODUCTION OF PLASTIC CONTAINER) www.irjet.net/Volume: 03 Issue: 04 | Apr-2016

6] Alexis Baltazar y Jimenez*Av Cultura 219 Universitaria, San Luis Potosi, SLP, Mexico 78290, $\begin{array}{llllll}\text { Telephone }+52 & 4448 \quad 13 & 88 & 94 . & \text { Email: }\end{array}$ alexisbalta@hotmail.com,

alexis_baltazar@hotmail.com(Literature

Review

Prevention and Reduction of Plastic Waste in European Automotive Producers) Received: 10 July 2001 Accepted: 30 November 2002

7] Madalina Elena Grigore(Methods of Recycling, Properties and Applications of Recycled Thermoplastic Polymers), Faculty of Engineering in Foreign Languages, University Politehnica of Bucharest, 313 Independen,tei Avenue, Sector 6, Bucharest 060042, Romania.

\section{REFERENCE}

[1] Decker, R. \& Graff, A. Paper Vs. Plastic Bags? Can be viewed at: http://www.angelfire.com/wi/PaperVsPlastic 